\title{
Para Uma leitura Teológica De Caim, de José Saramago
}

\author{
TOWARDS A THEOLOGICAL READING OF CAIM OF JOSÉ SARAMAGO
}

Marcus Aurélio Alves Mariano(*)

\begin{abstract}
RESUMO
"Deus" é um tema valioso para o escritor português José Saramago e se encontra presente nas suas numerosas obras. No seu último romance, Caim, o autor narra um duelo entre os personagens "deus" e "caim", provocando o leitor a uma opção por "caim", bom e honesto, e contra "deus", irresponsável e arrogante. O duelo se realiza com uma paródia irônica dos episódios bíblicos do Antigo Testamento e não se finaliza com a morte de "deus", mas com a permanência deste enquanto questão inconclusa e com divinização do ser humano. Propomos, neste artigo, uma leitura do romance Caim sob uma óptica teológica, a fim de discutir a imagem de deus que José Saramago apresenta no livro. Saramago se opõe a uma imagem institucional de deus veiculada pelas instituições religiosas milenares, sobretudo judaísmo e cristianismo. Ele propõe uma fé no ser humano sem crenças religiosas ou um deus no humano livre capaz do bem.
\end{abstract}

Palavras-Chave: José Saramago. Caim. Deus. Religião. Ateísmo.

\begin{abstract}
"God" is a valuable topic for the portuguese writer José Saramago and it is present in his numerous works. In his latest novel "Caim", the author narrates a duel between the characters "deus" and "caim", teasing the reader to decide for "caim" good and honest, or "deus" irresponsible and arrogant. The duel happens with an ironic parody of the biblical episodes of the Old Testament and it does not end with the death of "deus", but with the permanence of this as an unfinished question and deification of human beings. It is proposed in this article a reading of the novel "Caim" under a theological perspective to discuss god's image that José Saramagopresents on the book.Saramagoopposes an institutional god's image conveyed by the ancient religious institutions, especially Judaism and Christianity. He proposes a faith in man without religious beliefs or a god in free human capable of good actions.
\end{abstract}

KEYWORDS: José Saramago. Caim. God. Religion. Atheism.

\section{INTRODUÇÃO}

A Teologia é a ciência cujo objeto de pesquisa é Deus. No caso específico da Teologia Cristã, tal objeto deve ser pensado a partir da Revelação apresentada nas Escrituras e na Tradição. No entanto, falar “de" ou "sobre” Deus não se restringe à Teologia, mas estende-se a muitas outras ciências e saberes.

\footnotetext{
${ }^{(*)}$ Doutorando pela Faculdade Jesuíta de Filosofia e Teologia (FAJE) e pela Universidade Católica de Louvaina. Bacharel e mestre em teologia pela Faculdade Jesuíta de Filosofia e Teologia (FAJE). Bacharel em filosofia pela Universidade Estadual do Ceará (UECE). Email: irmaomarcus@gmail.com
} 
A Literatura, enquanto expressão escrita das mais diversas realidades humanas, também põe a questão de Deus e Deus em questão. Diversas obras e autores da história da Literatura universal privilegiaram o tema "Deus", de forma a oferecer para quem pesquisa Teologia elementos a partir dos quais se vê, no espelho do texto, Aquele que foi revelado e se tornou a matéria para os teólogos. A Literatura não possui censura, nem o rigor do discurso científico, por isso pode expressar-se livremente por meio de diversos gêneros a profundidade do interior humano.

José Saramago assume como propósito a tarefa de refletir sobre a questão de Deus em suas obras (FERRAZ, 20112a; SOUSA, 2012)ํ. O mais intrigante de pesquisar esse tema em Saramago é porque o autor milita contra a religião e contra Deus. Contudo, tanto um quanto outro perfazem o tecido da sua obra literária.

Por sua postura deicida e irônica em relação aos temas da fé e da religião, Saramago foi exilado por um período. Sua publicação mais estrondosa foi " $O$ evangelho segundo Jesus Cristo", em 1991. Esse quinto evangelho parodia e carnavaliza os evangelhos canônicos (Mateus, Marcos, Lucas e João) e apresenta uma boa notícia dos homens e para os homens na defesa de humanismo contra a tirania da religião cristã. A ousada escrita incitou a Igreja de Portugal às reações contrárias a Saramago (LOPES, 2010, p. 124-125). O governo português, por meio de Sousa Lara, secretário de Estado e Cultura, vetou a obra de Saramago por ser polêmica e atacar os princípios da religião.

A controvérsia de alguns setores da Igreja contra Saramago chega à censura pública:

Contudo, agora tratava-se de uma censura de caráter inquisitório tornada pública e publicamente justificada a partir do seio do governo em um gesto que fazia lembrar o caso tão polêmico da perseguição dos fundamentalistas islâmicos contra os versos satânicos de Salman Rushdie, pois trazia em si mesma a essência de ato estatal contra a liberdade de criação artística em nome de valores religiosos. (LOPES, 2010, p. 127).

No caso do romance "Caim", o autor continua sua árdua tarefa de combater Deus, ou sua imagem tradicional apresentada pelas religiões. O duelo já apresentado em outras obras continua nesta obra. Assim, elegemos seu último romance como lugar a partir do qual poderemos pensar teologicamente quem é o Deus de Saramago.

1 Salma Ferraz percorre cinco romances de José Saramago ("Terra do pecado"; "Memorial do convento"; "História do cerco de Lisboa"; "O evangelho segundo Jesus Cristo"; "Caim") para apresentar o itinerário da compreensão de Deus que Saramago possui. Ronaldo Souza elenca ainda "Manual de pintura e caligrafia" e "Levantando o chão" para análise do tema. 
Para tanto, observaremos como Saramago apresenta, por meio dos episódios dos personagens, uma imagem de Deus e o que tal imagem provoca no leitor. Como se trata de uma paródia do texto bíblico, observaremos as semelhanças e as referências que o autor recorre para elaboração de sua tentativa de matar a Deus a partir de Caim.

Nossa abordagem consiste num diálogo teológico respeitoso com a obra literária, vendo nesta um "lugar teológico". Conforme apresentado e discutido por Barcellos (2000, p. 27), utilizaremos um paradigma heurístico, investigando a obra literária e priorizando o método teológico. Comentaremos as passagens do romance com atenção aos personagens, aos diálogos e à possível intenção do autor. A imagem de Deus se constrói ao longo da narrativa e, a partir da análise no artigo, desvelaremos uma "teo-logia" saramaguiana.

Por fim, concluiremos com o monumento erigido e identificando qual Deus Saramago apresenta a partir dessa obra literária. A proposta humanista do deicida Saramago acaba por revelar o divino no humano ou o humano como lugar divino.

\section{1 “ CAIM” DE JOSÉ SARAMAGO”}

A última obra literária de José Saramago, o romance "Caim", publicado em 2009, apresenta o personagem bíblico Caim em duelo constante com Deus a partir de alguns relatos narrados no Antigo Testamento bíblico.

A clausura de quase meio século de trajetória literária acontece com um tema caro ao escritor: as contradições da relação entre o humano e o divino. A crítica à tradição religiosa, o elo entre narrativa e convicções políticas, o coloquialismo linguístico e a ironia satírica caracterizam o romance em análise (SANTOS, 2013, p. 31-32). O escritor usa o primeiro assassino da humanidade, conforme os relatos bíblicos, para inquirir proposições valiosas da tradição judaico-cristã.

Originalmente, em Gn 4,1-16, Caim é o primogênito do casal Adão e Eva e cultivava o solo, enquanto seu irmão mais moço, Abel, era pastor de rebanhos. Os dois oferecem a Deus um sacrifício dos produtos dos respectivos trabalhos: Caim, a colheita; Abel, a gordura do rebanho. Entretanto, Deus se agrada mais da oferenda de Abel. Então, Caim convida o irmão para sair e o mata. Deus procura por Abel e dialoga com Caim:

“Onde está teu irmão Abel?” Ele respondeu: “não sei. Acaso sou guarda de meu irmão?" - Que fizeste? Perguntou ele. "Do solo está clamando por mim o sangue do teu irmão! Por isso, agora serás amaldiçoado pelo próprio solo que engoliu o sangue do teu irmão que tu derramaste. Quando cultivares o solo, ele te negará 
seus frutos e tu virás a ser um fugitivo vagueando sobre a terra”. Caim disse ao Senhor: "Meu castigo é grande demais para que eu possa suportar. Se hoje me expulsas deste chão, devo esconder-me de ti, quando estiver fugindo e vagueando pela terra; quem me encontrar vai matar-me". Mas o Senhor lhe disse: "Se matarem Caim, ele será vingado sete vezes". O Senhor pôs um sinal em Caim para que ninguém, ao encontrá-lo, o matasse. (Gn 4,9-14)

José Saramago toma as dores do personagem bíblico Caim no romance e questiona as ações de Deus em relação à humanidade a partir dos seguintes relatos bíblicos: Adão e Eva no paraíso; a oferenda Caim e Abel; Abraão e Isaac; a Torre de Babel; a destruição de Sodoma e Gomorra; Moisés no Sinai; a tomada de Jericó; o sofrimento de Jó e a construção da arca de Noé até o dilúvio.

Caim e Deus se tornam os dois protagonistas do romance que narra a saga de caim, a participação dele em todos esses acontecimentos mencionados e o duelo com o senhor, também conhecido como deus, por causa de suas más ações, atitudes desleais e cruéis ${ }^{2}$.

\section{O PARAÍSO INICIAL}

O romance começa no jardim do Éden, com adão e eva, no qual deus num acesso de ira dá ao casal língua, a partir da qual os seres humanos podem criar idiomas e se comunicar uns com os outros. Deus comunica-se com o casal e os deixa em sua rotina conjugal para gerarem caim, abel e set. Como no relato bíblico (Gn 2-3), o casal recebera a interdição para não comer do fruto proibido, mas desobedecem e comem da maçã. Por esse ato, deus volta ao paraíso para reencontrálos e puni-los. Os dois são expulsos do jardim e habitarão uma terra árida e inóspita. Desde o início, o personagem deus possui caraterísticas humanas: irado, ausente, cego com adão e eva, irônico e com ações malvadas contra os seres humanos (SARAMAGO, 2009, p. 9-10)3. Os humanos passam a sofrer a sentença de deus: fome, sede, desproteção, cansaço, doenças entre outras coisas. "Neste caso, deus surge como este repressor que proporciona o 'mal' para o casal, primeiro para reprimi-los e, depois, expulsando-os do paraíso” (SILVA, 2012, p. 219). O leitor, desde o início, cria uma antipatia por deus.

\section{O Julgamento de Deus EM “CAIM”}

\footnotetext{
2 José Saramago faz uma opção por grafar os nomes próprios com iniciais em minúscula. Assim, manteremos a grafia do autor no nosso texto com o itálico para referir-se aos personagens caim, deus e os outros. Além disso, Saramago modifica os sinais de pontuação e promove uma maior fluência no texto a ponto de a voz do narrador e dos personagens se confundirem como se perceberá nas citações literais do romance.

3 Sobre a análise psicológica do personagem deus: SUMAM, 2012, p. 1-11.
} 
Os personagens caim e abel são apresentados como os melhores amigos um do outro (SARAMAGO, 2009, p. 32). O divisor dos irmãos é a oferta das primícias do trabalho a deus: a oferta de abel agradou a deus e caim levou seu irmão para um vale próximo e o matou a golpes de uma queixada de jumento (SARAMAGO, 2009, p. 34). O culto gerou violência, guerra e separação. Então, deus aparece, cheio de pompas como quando expulsou os pais do paraíso, reclama a vida de abel e discute com caim. A resposta de caim responsabiliza deus pela morte do irmão:

matei abel porque não podia matar-te a ti, pela intenção estás morto, Compreendo o que queres dizer, mas a morte está vedada aos deuses, Sim, embora devesse carregar com todos os crimes cometidos em seu nome ou por sua causa, Deus está inocente, tudo seria igual se não existisse, Mas eu, porque matei, poderei ser morto por qualquer pessoa que me encontre (...) (SARAMAGO, 2009, p. 35) 4.

No romance, deus é culpabilizado pela morte de abel. Ademais, caim comete o assassinato contra o irmão devido a impossibilidade de matar deus. Em seguida, deus marca caim com um sinal para que ninguém o mate e ainda receberá, igualmente aos pais, um castigo divino: andará errante e perdido no mundo com uma mancha negra sobre a testa como o sinal da condenação. No entanto, caim, pelo mesmo sinal que o condena, recebe a proteção e a vigilância de deus. Com isso, o leitor é logo advertido: "ao matar abel por não poder matar o senhor, caim deu já sua resposta. Não se augure nada de bom na vida futura deste homem" (SARAMAGO, 2009, p. 37).

\subsection{Início da saga}

A saga do personagem principal se inicia: ele se envergonha do sinal na testa, sofre procurando abrigo, mente dizendo ser abel, até chegar, por indicação de um velho, às terras de nod, que significa terra da fuga ou terra dos errantes (SARAMAGO, 2009, p. 45) ${ }^{5}$, onde trabalhou amassando barro. Trabalhando nestas terras, caim conhece lilith $^{6}$, a rainha ou dona da cidade, e torna-se o melhor amante dela. Ela mandou chamá-lo para sua câmara a fim de satisfazer seus desejos sexuais. Ao chegar, caim entra pela porta principal (nenhum segredo em ter amantes), é limpo pelas criadas de litith e fica a sós com a nova dona para que ela o devore:

\footnotetext{
4 Manteremos a mesma pontuação e o mesmo uso de maiúsculas e minúsculas do texto de Saramago.

5 De fato, etimologicamente, a palavra hebraica nad significa errante. Foi para esta região, segundo o relato bíblico (Gn 4,16), que Caim foi habitar distante do Senhor e aí gerou sua descendência (Gn 4,17-24).

${ }^{6}$ Tal personagem não aparece nos relatos bíblicos, mas é tomada da mitologia. "Senhora de Nod, esposa de noah. Belíssima e dominada pela luxuria. Costuma retirar operários da construção de seu palácio e promove-los a porteiros da antecâmara de seu quarto (um eufemismo para amante). (...) O prazer que caim desperta em lilith também desperta os ciúmes de noah, que planeja matar o amante (porém a tentativa fracassa)". FERRAZ, 2012b, p. 204.
} 
"porque lilith, quando finalmente abrir as pernas para se deixar penetrar, não estará a entregar-se, mas sim a tratar de devorar o homem a quem disse, Entra" (SARAMAGO, 2009, p. 59).

O amassador de barro promovido a porteiro e a amante preferido da rainha não se cansa, tampouco lilith se sacia nas noites e dias sucessivos com caim. $\mathrm{O}$ marido noah toma conhecimento daquele fato. Ele não se importava com os outros amantes devido a sua incapacidade de gerar filhos em lilith, no entanto, por ciúmes, quis matar caim e lilith diante de tantos desejos satisfeitos. Um atentado com os escravos é preparado contra a vida de caim, ele se salva por causa da sua marca na testa. Depois disso, caim resolve abandonar a cidade e lilith para seguir afora montado num jumento. Em meio às desventuras de caim e lilith, o inimigo de caim, deus, não é mencionado diretamente. Onde deus estaria?

\subsection{Com abraão e isaac}

As viagens de caim não são apenas no espaço, mas também no tempo. Como observa Salma Ferraz: "O romance é um transe alucinógeno entre as paisagens e passagens centrais do Velho Testamento" (FERRAZ, 2012a, p. 221). Deixando nod, encontra-se com o jovem isaac levado pelo seu pai abraão para o sacrifício. Saramago apresenta deus com alguém perverso em quem não se deve confiar7, pois pede a abraão o sacrifício do próprio filho isaac (cf. Gn 22, 1-19). O herói caim aparece, antes do que o anjo do senhor, no momento exato para segurar a mão de abraão, pedir que desate isaac e desista das ordens do senhor. O jovem isaac então questiona ao pai sobre o que iria sofrer sem a intervenção de caim, abraão responde:

A ideia foi do senhor, que queria tirar a prova, A prova de quê, Da minha fé, da minha obediência, E que senhor é esse que ordena a um pai que mate seu próprio filho, É o senhor que temos, o senhor dos nossos antepassados, o senhor que já estava quando nascemos, E se esse senhor tivesse um filho, também mandaria matar, perguntou isaac, O futuro dirá, Então o senhor é capaz de tudo, do bom, do mau e do pior (SARAMAGO, 2009, p. 82).

Enfim, caim se torna o salvador da vida de isaac contra a crueldade de deus. De amante da rainha ele passa a ser o herói dos primeiros pais da fé da religião dos judeus. O velho abraão deveria acreditar mais em caim do que em deus.

\footnotetext{
7 "O senhor não é uma pessoa em quem se possa confiar" (SARAMAGO, 2009, p. 78). "O leitor leu bem, o senhor ordenou a abraão que lhe sacrificasse o próprio filho, com a maior simplicidade o fez, como quem pede um copo de água quando tem sede, o que significa que era costume seu, e muito arraigado. O lógico, o natural, o simplesmente humano seria que abraão tivesse mandado o senhor a merda, mas não foi assim". (SARAMAGO, 2009, p. 79).
} 


\subsection{A torre de Babel}

Seguindo viagem, caim se defronta com uma alta torre, a Torre de Babel (cf. Gn 11,1-9), na qual pessoas falavam e gritavam sem se entenderem. A torre foi construída para atingir os céus, o que desagradou ao ciumento e invejoso deus, que, não suportando o êxito dos seus filhos, manda um vento forte para destruir a torre sem deixar pedra sobre pedra, pois o orgulho do senhor não consentiu que se terminasse a obra. Saramago conclui o episódio acentuando a dramática relação entre os homens e Deus: "a história dos homens é a história dos seus desentendimentos com deus, nem ele nos entende, nem nós o entendemos a ele" (SARAMAGO, 2009, p. 88).

\subsection{Sodoma e Gomorra}

Depois, há um novo encontro entre caim e abraão, desta vez sob sua tenda, que o relato bíblico chama de carvalho de Mambré (cf. Gn 18,1-15) ${ }^{8}$. Além de caim, o encontro na tenda de abraão era com mais três homens, dentre eles, o senhor deus disfarçado de humano e que faz sara rir com a promessa de um filho naquela idade avançada. Em seguida, abraão dialoga com deus pedindo por Sodoma e Gomorra (Gn 18,16-33), pois seus crimes contra a natureza chegaram a deus, o imparcial juiz (SARAMAGO, 2009, p. 92). O velho abraão pede a deus que não destrua a cidade em consideração aos dez justos que vivem lá, entretanto, caim desconfia de que deus cumpriria sua palavra. Então, os dois partem para a cidade, chegam à casa de lot, hospedam-se, preparam a fuga dos parentes de abraão e saem às pressas enquanto as cidades são destruídas pelo senhor. A mulher de lot olha para trás e se transforma numa estátua de sal, conforme o relato bíblico Gn 19,26, e é punida9. O justo caim percebe que não tinham inocentes naquelas cidades, mas recorda-se das crianças que foram mortas pela maldade divina: "as crianças, disse caim, aquelas crianças estavam inocentes, Meu deus, murmurou abraão e sua voz foi como um gemido, Sim, será o teu deus, mas não foi o delas" (SARAMAGO, 2009, p. 97).

\footnotetext{
${ }^{8}$ Saramago faz caim viajar no espaço e no tempo e embaralha propositalmente os relatos bíblicos. Na Bíblia, o episódio agora narrado acontece antes do nascimento de Isaac. No romance, caim pergunta a abraão por isaac e ele responde que só tem o filho ismael (cf. SARAMAGO, 2009, p. 89). O personagem caim possui uma relativa onipotência e onipresença.

9 Saramago aproveita o acontecimento para um juízo sobre deus: "Até hoje ainda ninguém conseguiu compreender por que foi ela castigada desta maneira, quando tão natural é querermos saber o que se passa nas nossas costas. É possível que o senhor tivesse querido punir a curiosidade como se tratasse de um pecado mortal, mas isso também não abandona muito a favor de sua inteligência” (...). (SARAMAGO, 2009, p. 97).
} 


\subsection{No Sinai}

De Sodoma caim vai ao Sinai e se encontra com uma multidão no sopé do monte, aguardando moisés descer do alto, uma referência a Ex 32. Descendo do monte, moisés encontra o povo praticando idolatria, adorando um bezerro de ouro que fora construído por eles. Irritado, moisés reúne os homens da tribo de Levi e, sob as ordens do senhor, mata cerca de três mil homens. Não bastando a crueldade da destruição de Sodoma e Gomorra, caim testemunha a maldade de deus por inveja de um bezerro de ouro (SARAmago, 2009, p. 101). Ao final da matança, o senhor ordenou a moisés e aos sacerdotes a repartição dos despojos da guerra. Saramago descreve a vergonhosa ação de deus: "Agora, o senhor esconde-se em colunas de fumo, como se não quisesse que o vissem. Em nossa opinião de simples observadores dos acontecimentos andará envergonhado por algumas tristes figuras que tem feito, como o caso das inocentes crianças de Sodoma que o fogo divino calcinou" (SARAMAGO, 2009, p. 108).

\subsection{Cerco de Jericó}

A próxima ação de caim será como aliado do exército de josué na cidade de jericó (Js 6-10). Depois de sete dias dando voltas na cidade, as muralhas caíram e a matança começou. Enquanto isso, o senhor, que não estava na coluna de fumo, era uma voz que ressoava nos vales (SARAMAgo, 2009, p. 113). Além de matar, os soldados roubam os mortos e levam consigo os despojos da guerra. Tal fato provoca uma repugnância no justo caim, que se põe em macha para deixar a cidade no seu burro. O chefe josué vai à tenda para pedir ao senhor que pare o sol, mas o desejo do senhor é a morte dos amorreus. O sol fica parado para que josué vença os amorreus e agrade a deus. Além de se deliciar com a guerra e a morte de milhares, deus engana aos homens com alguns feitos para alcançar seus objetivos ${ }^{10}$.

\subsection{Reencontro com lilith}

O burrico de caim o conduz para um novo lugar. Ele reencontra o velho e escuta do velho que lilith engravidara e tinha um filho dele. Subitamente, caim vai em busca de reencontrar lilith e seu filho. Ele conhece enoch, seu filho, e visita lilith. Os dois reviveram o que sentiam falta por dez anos passados e caim a atualiza dos vários episódios de suas andanças e das lastimáveis atitudes divinas:

Não sei se fui escolhido, mas algo sei, sim, algo devo ter aprendido, Quê, Que o nosso deus, o criador do céu e da terra, está rematadamente louco, Como te

\footnotetext{
10 O personagem deus já conhece o heliocentrismo e reconhece não poder parar o sol, mas trama com josué fazer o possível para a vitória dele acontecer durante a luz dia para que todos pensem que deus parou o sol. Só deus e josué sabem do segredo ( SARAMAGO, 2009, p. 118-121).
} 
atreves a dizer que o senhor está louco, Porque só um louco sem consciência dos seus actos admitiria ser o culpado directo da morte de centenas de milhares de pessoas e comportar-se depois como se nada tivesse sucedido, salvo, afinal, que não se trate de loucura, a involuntária, a autêntica, mas de pura e simples maldade (SARAMAGO, 2009, p. 128).

\subsection{Questões à job}

A próxima cidade que caim visita é Us. Ele se encontra com job, homem rico, para quem se propõe trabalhar. Na labuta cotidiana, dois anjos aparecem e contam a caim que houve uma reunião dos seres celestiais e satã pediu para tentar a fidelidade de job, isto é, o senhor e satã fizeram uma aposta como consta em Jó 1,6-22. A ocasião provoca caim a expressar sua indignação contra deus: "estou cansado da lengalenga de que os desígnios de deus são inescrutáveis, respondeu caim, deus deveria ser transparente e límpido como cristal em lugar desta contínua assombração, deste constante medo, enfim, deus não nos ama” (SARAMAGO, 2009, p. 135). De nada adiantaram os questionamentos de caim para os anjos.

Os ataques de satã a job começaram quando seus filhos estavam à mesa a beber vinho. Um mensageiro após outro trazia notícias de catástrofes nos bens de job. Diante daquilo, o servo job se prostra reverente e ora a deus. Tal fato, causa tremenda indignação em caim, pois satã dispõe dos sabeus e dos caldeus para serviço de seus interesses e serve-se de um fenômeno natural para fazer o mal contra o fiel job. O personagem satã se torna o encarregado de executar os trabalhos sujos de deus. A aposta foi ganha por deus: job não o renegou. Montando um jumento, caim seguiu para um novo rumo, irritado com a situação do patrão job de quem nem se despede.

\subsection{O último paraíso}

A nova estação de caim será um lindo lugar, substituto do édem, onde se depara com a construção de uma grande arca (Gn 6,9-8,22). Diante do grande engenho, caim interroga do que se trata, mas noé e seus três filhos continuam o trabalho. Então, o senhor aparece-lhes pirotecnicamente e caim, aborrecido, contrapõe-se ao senhor por seus feitos passados advogando a favor das vítimas humanas. Os dois parecem dois velhos amigos que se encontraram depois de longa separação. O senhor ordena a noé a ocupação da arca para iniciar a destruição da humanidade.

O andante caim retruca a criatividade divina e corrige o lugar da construção da arca. Responde caim ao senhor: 
Os teus cálculos estão errados, um barco deve ser construído junto à agua, não num vale rodeado de montanhas, a uma distância enorme do mar, quando está terminando empurra-se para a água e é o próprio mar ou rio, se for esse o caso, que se encarregam de o levantar, talvez não saibas que os barcos flutuam porque todo corpo submergido num fluido experimenta um impulso vertical e para cima igual ao peso do volume do fluido desalojado, é o princípio de Arquimedes (SARAMAGO, 2009, p. 152).

Por causa de caim, deus mudou os planos de destruir a espécie humana e ordenou aos anjos que ajudassem no término da arca. O senhor sumiu e reapareceu para saber da ocupação de caim. O obediente noé responde que ele já dormira com duas de suas noras e se preparava para dormir com a terceira. Depois, noé se ocupa em reunir os animais para a continuidade das espécies.

Enquanto as espécies se preparavam para o dilúvio, deus se ocupava solitariamente com o sistema hidráulico do planeta ${ }^{11}$. Num instante seguinte, a arca deixara o chão, fora suspensa pelos anjos operários, carregada ao ar e levada ao mar. Todos estavam seguros na arca enquanto o dilúvio acontecia. No interior da arca, noé ofereceu um sacrifício de agradecimento ao senhor e é eleito como o pai da nova humanidade. No decorrer dos dias, algumas mortes ocorrem entre aquela pequena mostra da humanidade, as pessoas diminuem até ficarem apenas duas mulheres, sem, noé e caim ${ }^{12}$.

Finalmente a arca toca a terra firme. O senhor imediatamente chamou noé para que saísse com os animais para repovoarem a terra. Do interior da arca, em vez de sair noé, o evocado pelo senhor, sai caim, pois os outros foram mortos por caim e noé se suicidou afogando-se. Então, como no início do romance, deus pede contas a caim: "como te atreveste, assassino, a contrariar o meu projecto, é assim que me agradeces ter-te poupado a vida quando mataste abel, perguntou o senhor" (SARAMAGO, 2009, p. 172).

O conflito entre caim e deus parecia chegar ao fim. Os dois inimigos estavam face a face. A humanidade estava destruída pelo dilúvio e restava o assassino caim, que pedia o fim de sua vida. Porém, deus reponde a caim: "Não posso, palavra de deus não volta atrás, morrerás da tua natural morte da terra abandonada e as aves de

\footnotetext{
11 "Deus não veio ao bota-fora. Estava ocupado com a revisão do sistema hidráulico do planeta, verificando o estado das válvulas, apertando alguma porca mal ajustada que gotejava onde não devia, provando as diversas redes locais de distribuição, vigiando a pressão dos manómetros, além de uma infinidade de outras grandes e pequenas tarefas, cada uma delas mais importante que a anterior e que ele só, como criador, engenheiro e administrador dos mecanismos universais, estava em condições de levar a bom termo e confirmar como o seu sagrado o.k." (SARAMAGO, 2009, p. 161). O solitário deus não possui amigos, apenas servos. O supremo arquiteto se exclui da companhia alegre dos homens e anjos.

12 "Das oito pessoas que compunha a família de noé só restavam agora, além do próprio patriarca, o seu filho sem e a mulher e a viúva de jefet" (SARAMAGO, 2009, p.170).
} 
rapina virão devorar-te a carne, Sim, depois de tu primeiro haveres devorado o espirito" (SARAMAGO, 2009, p. 172). Os dois continuaram a discutir e a argumentarem um contra o outro. O romance acaba com os dois em duelo, nem caim mata a deus, nem deus mata caim.

O romance trata, do início ao fim, do atrito entre caim e deus. O personagem principal se torna o juiz de deus no enredo. No início e no fim o romance ocorre num paraíso, seja nos primórdios de adão, seja na nova criação da humanidade depois do dilúvio. Em vez de aliança entre os dois, uma rivalidade. Os dois assassinos deverão suportar um ao outro sem tirar a vida um do outro.

\section{SARAMAGO: DEICIDA CRENTE}

A partir do romance, o duelo entre caim e deus reflete o confronto de uma mentalidade pós-moderna com as representações de Deus. Por diversos meios, o tema da "morte de Deus" foi proclamado na contemporaneidade e José Saramago foi um dos seus arautos. No entanto, a ideia de Deus permanece na linguagem, na reflexão e no interesse do autor. O personagem deus do romance "Caim" mostra o valor que o tema tem para Saramago.

O personagem antagonista do herói caim demonstra-se perverso, arrogante, vaidoso, arbitrário, irresponsável, distante, sem misericórdia e que não se importa tanto com o ser humano, agindo malevolamente contra sua criação. Longe das características tradicionais do Deus da fé das religiões, Saramago apresenta uma divindade ausente e concorrente com o ser humano, do qual o ser humano deveria se livrar para não atrapalhar a própria vida e a vida dos seus familiares. $O$ deus de Saramago provoca mais revolta interior do ser humano do que sentimentos de paz, amor e fraternidade; mais atrapalha a humanidade com suas erradas intervenções do que promove o bem entre as pessoas. O leitor é conduzido a uma repugnância ao personagem deus e a tomar partido por caim, símbolo do humano emancipado, independente de crenças e da divindade.

O personagem caim é descrito com simpatia por Saramago. Ele torna-se o advogado das pessoas de bem que sofrem e o herói que as "salva" das cruéis ordens divinas. A revolta de caim contra deus e as questões postas por ele contra seu antagonista mostram o conflito entre bem e mal e entre deuses e homens. Caim é aquele que age corretamente, enquanto deus age errado; caim é a favor da humanidade, enquanto deus contra ela; caim é correto, ético e bondoso, enquanto deus é incorreto, irresponsável e malvado. Alguém como o personagem deus do romance "Caim" desejamos nos livrar e exorcizar da humanidade. 
Com toda a pujança de deus, caim não consegue se libertar do jugo da relação com ele, tampouco Saramago. Os atritos do princípio ao fim do livro demonstram uma tentativa de convencer o leitor da inutilidade de deus, de quanto mal deus faz a quem acredita nele e de que caim é melhor do que deus. No entanto, Saramago assume a impossibilidade de se livrar de deus. A vontade de matar a Deus fracassou e, nem que seja como uma questão, Deus permanece vivo.

Salma Ferraz, ao contrário, considera que, no romance "Caim”, Saramago vela o cadáver de Deus e depois crema as suas cinzas:

Se ao longo de sua obra, Saramago vai diretamente ou indiretamente cutucando o caráter nada santo de Deus por meio de falas de personagens ou revisitando episódios bíblicos, se n'O Evangelho Segundo Jesus Cristo, revela um Jesus humano vítima de Deus cruel, se havia revisitado antes em vários de seus romances episódios do Velho Testamento, em 2009 publica o romance Caim, no qual um autor ateu e deicida cria um personagem deicida. Se n'O Evangelho Segundo Jesus Cristo (1991), o autor mata Deus, em Caim (2009), ele vela o cadáver de Deus e depois crema suas cinzas. Quase vinte anos separam uma obra da outra (FERRAZ, 2012a, p. 205).

O autor português não se propõe a questionar ou negar a existência de Deus. Ele apresenta uma versão literária de Deus por meio de uma reescrita jocosa, de uma paródia dos episódios bíblicos e da construção de um diálogo intertextual com os textos sagrados (FERraz, 2012a, p. 231). Com isso, ele constrói ironicamente uma imagem repugnante de Deus. Para Saramago, Deus existe e é terrível, por isso, não se deve acreditar nem esperar nele. $\mathrm{O}$ autor se opõe à imagem tradicional de Deus construída pelas religiões, sobretudo pela religião judaico-cristã. Saramago demonstra ter fé na humanidade emancipada das crenças, no homem correto e ético, na humanidade sacralizada (SOUSA, 2012, p. 189), o que Jaime Sant'anna chama de um "ateísmo ético"13.

Saramago possui uma obsessão por Deus, personagem presente em diversas obras, no entanto, com uma implicância com o Deus que ele ouviu falar e passou a odiar. A implicância se deve às experiências de vida do autor com algumas formas históricas do cristianismo e por responsabilizá-lo por violências, intolerâncias e

\footnotetext{
${ }_{13}$ "Em suma, percebemos, tanto em Levantado do chão quanto no restante do corpus literário escolhido para este estudo, que o pensamento e a indignação de José Saramago eclodem de um forte desejo de justiça e como resposta à avalição da experiência religiosa ocidental. Ao mesmo tempo em que nega a existência do Deus cristão, Saramago rechaça veementemente toda sorte de injustiças que, antagonicamente, têm sido protagonizadas por uma sociedade que se intitula paradoxalmente cristã. Chamaremos a esta atitude presente na literatura de José Saramago de ‘ateísmo ético”' (SANT'ANNA, 2009, p. 54).
} 
injustiças (SANT'ANA, 2009, p. 43). José Saramago não aceita um Deus onipotente, que intervém no mundo, por isso o enaltecimento do ser humano além da divindade, simbolizado pelo personagem caim.

Saramago, em vez de ateu confessante, mais parece um crente anônimo, alguém com um tipo de fé incipiente. Tentando matar Deus, ele destrói uma figura de Deus, representação do poder e de ideologias desumanas, e deseja algo que se possa nomear de Deus, que sacie o desejo por transcendência que faz do ser humano mais humanos. Então, no humano, Saramago encontra a transcendência e caim é o profeta da religião do autor português.

O deicídio tentado não se concretiza no romance "Caim". Há a morte de uma imagem tradicional e dos crentes irresponsáveis, antiéticos e fanáticos. No silêncio da discussão em que se encerra o romance, encontramos o que impulsionou Saramago e sua questão principal: Deus. Saramago apresenta uma transcendência por demais imanente. Deus permanece no humano.

\section{REFERÊNCIAS}

BARCELLOS, José Carlos. Literatura e Teologia: perspectivas teórico-metodológicas no pensamento católico contemporâneo. Numem, Juiz de Fora, vol. 3, n. 2, p.9-30, 2000.

BÍBLIA de Jerusalém. São Paulo: Paulus, 2002.

FERRAZ, Salma. As faces de Deus na obra de um ateu. $2^{\text {a }}$ ed. Blumenau: Edifurb, 2012a.

FERRAZ, Salma. Lilith. In: FERRAZ, Salma. Dicionário de personagens da obra de José Saramago. Blumenau: Edifurb, 2012b, p. 204-205.

LOPES, João Marques. Saramago: biografia. São Paulo: Leya, 2010.

SANT'ANNA, Jaime. Em que crêem os que não crêem: o sagrado em José Saramago. São Paulo: Fonte editorial, 2009.

SANTOS, José Diego Cirne. A dialética da desalienação: uma leitura marxista do romance Caim, de José Saramago. João Pessoa: UFPB, 2013. 173 p. Dissertação (Mestrado em Letras) - Faculdade de Ciências Humanas, Letras e Artes, Universidade Federal da Paraíba.

SARAMAGO, José. Caim. São Paulo: Companhia das letras, 2009.

SILVA, Hudson Marques. Configurações do mal no romance Caim, de José Saramago. In: MAGALHÃES, Antônio Carlos de Melo. O demoníaco na literatura. 2012, p. 215-223. 
SOUZA, Ronaldo Ventura. Figurações de Deus nos Romances de Saramago. São Paulo: USP, 2012. 207 p. Tese (Doutorado em Letras) - Faculdade de Filosofia, Letras e Ciências Humanas, Universidade de São Paulo.

SUMAM, Guilherme. Caim: a psicologia de Deus na obra de José Saramago. Nau Literária, Porto Alegre, vol. 8, n. 2, p. 1-11, jul-dez 2012.

Recebido em 12/02/2016 Aprovado em 27/o6/2016 